\title{
The Economic Benefits of Supported Employment for Persons with Mental Illness
}

\author{
Robin E. Clark ${ }^{1 *}$, Bradley J. Dain ${ }^{1,2}$, Haiyi Xie ${ }^{1}$, Deborah R. Becker ${ }^{1}$ and Robert E. Drake ${ }^{1}$ \\ ${ }^{1}$ Departments of Community and Family Medicine and of Psychiatry, New Hampshire-Dartmouth Psychiatric Research Center and Dartmouth Medical \\ School, Hanover, NH, USA \\ ${ }^{2}$ Pharmaceutical Division, Bayer Corporation
}

\begin{abstract}
Background: Policies and programs that emphasize employment for persons with mental illness are often promoted with the goals of improving economic self-sufficiency and reducing dependence on public welfare programs. At present, there is little empirical evidence about the actual effect of vocational interventions on economic self-sufficiency or on use of public benefits by persons with mental illness.
\end{abstract}

Study Aims: This study provides a preliminary look at how participating in supported employment, a form of vocational rehabilitation emphasizing ongoing support in competitive jobs, affects the amount that participants earn from work and the total amount of income they receive from all sources. Further, we examine the extent to which receiving public benefits affects the amount earned from private employment, taking into consideration other factors that might be associated with benefit status.

Methods: Data are from a randomized trial of supported employment interventions. This analysis followed 137 of those study participants with severe mental illness for 18 months after they enrolled in either of two supported employment programs. Income from various sources was estimated based on interviews with study participants upon study entry and at six-month intervals thereafter. Changes in income from work, government and other sources were analyzed using paired Wilcoxon matched-pairs signed-ranks tests and $t$-tests. Using ordinary least-squares regression, we analyzed the effect of benefit status on changes in earnings, taking into account diagnosis, work history, education, program type, site of program, psychiatric symptoms, global functioning and previous earnings.

Results: Estimated total income increased by an average of $\$ 134$ (US) per month after enrolling in supported employment. More than three-quarters of this increase was from government sources, such as Social Security and educational grants. The increase in government income was largely due to participants applying for and getting cash benefits for the first time. Social Security payments for those receiving benefits before enrollment did not change significantly. A small group of persons $(n=22)$ who did not

\footnotetext{
* Correspondence to: Robin E. Clark, Dartmouth Medical School, Department of Community and Family Medicine, Strasenburgh 7250, Hanover, NH 03755-3862, USA. E-mail: robin.e.clark@dartmouth.edu. Contract grant sponsor: National Institute of Mental Health

Contract grant number: 00839

Contract grant sponsor: National Institute of Mental Health and the Substance Abuse and Mental Health Services Administration

Contract grant number: $\mathrm{MH}-47650$
}

receive Social Security benefits before or after enrolment earned significantly more from competitive employment after enrolling than did those who received benefits. This finding persisted after taking into acount differences in work history, clinical and functional variables and education.

Limitations: Because of the relatively small sample size and the lack of continuous measures of income these results should be considered preliminary.

Conclusions: Supported employment, one of the more effective forms of vocational rehabilitation for persons with mental illness, did not reduce dependence on government support. Receiving government benefits was associated with lower earnings from work.

Implications for Health Care Provision and Use: These findings suggest that most persons in treatment for severe mental illness need continued public financial support even after enrolling in vocational rehabilitation programs.

Implications for Health Policy Formulation: Undoubtedly increased labor force participation can benefit persons with mental illness in a number of ways. However, policy makers should be careful about justifying increased access to vocational programs on the basis of reduced spending for income support. Further, targeting such programs only to persons receiving income support may overlook the clients who can benefit most: those who are not currently receiving benefits.

Implications for Further Research: Policy makers need a better understanding of how vocational interventions and income support programs affect the income and well-being of persons with mental illness. Studies similar to this one should be repeated with larger, more diverse samples that will allow use of instrumental variables statistical techniques. (C) 1998 John Wiley \& Sons, Ltd.

Received 4 December 1997; accepted 17 April 1997.

\section{Introduction}

Making ends meet is a constant concern for persons with severe mental illnesses such as schizophrenia and bipolar disorder. Public welfare programs offer health insurance for a large number of people but provide meager support for basic living expenses. Although work at competitive wages might improve their financial well-being, labor force participation is quite low among persons with severe mental disorders. Traditionally, many observers have considered unemployment a natural consequence of mental illness. 
More recently, advances in treatment and rehabilitation, changes in laws and attitudes towards people with disabilities and attempts to reform public health and welfare programs have caused policy makers to reexamine the employability of persons with mental illness.

Based on the theory that welfare benefits reduce work motivation, attempts in the United States to reform federal, state and local welfare programs have tried to limit payments and to impose work requirements for beneficiaries. While much of this effort targets the former Aid to Families with Dependent Children (AFDC) program (now called Temporary Assistance for Needy Families: TANF), similar approaches have been discussed for disability programs such as Supplemental Security Income (SSI) and Social Security Disability Insurance (SSDI), which are more likely to support persons with severe mental illness.

Advocates for persons with mental illness view the shift towards more work-focused policies with ambivalence. Clearly, many people with schizophrenia, bipolar disorder and similar illnesses want to work in competitive jobs, for their own satisfaction as well as for economic reasons; ${ }^{1,2}$ clinicians often share their belief that work is therapeutic. ${ }^{3}$ However, what is desirable for personal, political or therapeutic purposes may have adverse economic consequences for individuals. Losing hard-won income and health benefits is a serious concern for anyone with a chronic illness.

Under current conditions, work appears to contribute relatively little to income growth for persons with severe mental illness. ${ }^{4}$ Most work part-time in low paying jobs. Cash benefits from SSI or SSDI may be reduced or permanently eliminated if earnings exceed pre-set limits. Losing public benefits without a realistic prospect of supporting themselves through earnings leaves persons with mental illness few options other than dependence on their families or homelessness. It is, therefore, vitally important that we know how policies and programs that encourage competitive employment affect total income.

Evaluations of vocational interventions typically compare wages earned but fail to consider explicitly how earnings affect participants' total income, including SSI, SSDI, food stamps, access to further education and training and so forth. Because earnings from work can reduce the amount of public income support and affect eligibility for medical assistance through Medicaid and Medicare (medical insurance programs for low-income, disabled and aged persons), an additional dollar earned from work often contributes much less than one dollar to a person's income. In cases where a person completely loses eligibility for a benefit, the longterm impact of earnings on total income could even be negative, particularly when a relapse prevents him or her from continuing to work. It is critically important to analyze the impact of employment-focused interventions on economic well-being, rather than to simply measure the number of hours worked or the amount earned from work.

In this paper we view the economic benefits of two supported employment programs from the perspective of participants, estimating the actual economic benefit to them from all sources. While program evaluations and cost- effectiveness analyses typically evaluate such interventions from the perspective of government expenditures or societal costs, we believe the individual economic perspective should be given equal consideration in policy decisions. The individual perspective offers unique insights into what persons with severe mental illness have to gain, and possibly to lose, from policies that encourage work in competitive jobs.

The purpose of this analysis is not to assess the relative effectiveness or cost-benefit of the two programs; that has been reported elsewhere. ${ }^{5,6}$ Here we focus on how vocational interventions and receipt of cash benefits affect consumers' incomes.

\section{Sources of Economic Support}

To evaluate the individual economic benefits of supported employment, we must understand the nature of current employment and financial support for persons with mental illness. Persons with severe mental illness have lower employment rates than do other disability groups. ${ }^{7}$ Although figures vary widely depending on the source of data and on the specific diagnostic groups studied, labor force participation is generally reported to be less than $50 \%$ among persons with severe mental illness living in the United States. It is likely that only a small proportion of those who work are able to support themselves exclusively with earnings.

Federally sponsored SSI and SSDI programs are the primary source of financial support for a large number of persons with mental illness. A relatively small proportion receive benefits from the Veteran's Administration, TANF, or other public programs. SSDI payments are based on the amount a person paid in Social Security payroll taxes prior to becoming disabled: those who paid more receive higher benefits. SSI provides a fixed amount of money for persons with a disability who are in financial need, without regard to their work history. As a general category, mental disorders are the most frequent and fastest-growing diagnostic classification for persons enrolled in both programs. ${ }^{8,9}$

SSI payments decrease as earnings increase; earnings above $\$ 65$ in each month reduce benefits by $\$ 1$ for every $\$ 2$ earned. SSDI beneficiaries can earn up to $\$ 200$ per month without affecting their benefits. Further, during an initial nine-month trial work period, SSDI beneficiaries can earn more than $\$ 500$ monthly without fear of losing benefits. Both programs offer provisions for helping persons continue eligibility for medical and income benefits for a period of time after their earnings exceed the substantial gainful activity (SGA) levels used to determine eligibility for benefits. During the period covered by this study SGA was $\$ 500$ for both SSI and SSDI recipients. SSDI beneficiaries who exceed SGA can maintain eligibility for 36 months after completing the nine-month trial work period. Although they do not receive payments when they exceed SGA levels, they can continue to receive medical benefits and remain eligible for cash payments if their earnings drop below the SGA level. SSI recipients who exceed SGA can maintain eligibility for Medicaid through section 1619(b) of Social Security rules, up to a predetermined amount of income. 
During 1994 the 1619(b) was \$23924 in New Hampshire. Although these provisions are important benchmarks, evidence suggests that most persons with severe mental disorders rarely exceed SGA levels.

Persons with mental disorders are among the least likely to terminate SSDI benefits because they have returned to work. Those who do leave are more likely to reapply for benefits at a later time than are people in most other disability groups. ${ }^{10}$ In the SSI program recipients with 'psychoses and neuroses' earn approximately the same amount from work as do those with other types of disability. Still, their average yearly earnings are quite low: $\$ 1015$ in $1988 .^{8}$

Despite the assertions of many pundits, we know relatively little about how public benefits affect work behavior. Studies of the AFDC and Veteran's administration programs suggest that public benefits may have a slight deterrent effect on work, ${ }^{11,12}$ but similar analyses of SSI and SSDI are more difficult. By definition, those who are eligible for such programs are likely to be more disabled than persons with similar diagnoses who are not enrolled. However, one comparison of successful and unsuccessful applicants for SSDI suggests that deterrent effects are relatively small and that functional health is the primary limiting factor in labor force participation. ${ }^{13}$

Even when they have public benefits, persons with mental illness often receive a substantial amount of informal help from family and friends. ${ }^{14}$ This support can take the form of gifts or loans of money, contributions of food or shelter and direct caregiving. Studies show that family assistance for persons with mental illness may play an important role in preventing homelessness. ${ }^{15,16}$ Despite these important contributions, few families can afford to be the sole source of financial support for a relative with mental illness.

Against this backdrop, vocational rehabilitation offers the promise of helping people with mental illness improve their economic condition by securing a competitive job. Work may also reduce their social isolation, boost self-confidence and allow them to participate more fully in their communities. However, as they earn more, persons with severe mental disorders give up some current benefits as well as future security. Given these potentially conflicting effects, the true economic benefits of vocational rehabilitation for persons with mental illness are not at all clear.

\section{Vocational Rehabilitation for Persons with Mental Illness}

Although specific vocational rehabilitation programs appear to be effective in helping people obtain jobs, their effect on overall income and benefits has not been carefully examined. In a study of people who received services from the Virginia Department of Rehabilitative Services during the early 1980s, Dean and Dolan ${ }^{17}$ found that, unlike persons with physical disabilities or mental retardation, participants labeled 'emotionally disabled' did not significantly increase their earnings after completing vocational rehabilitation services. This finding cannot be attributed confidently to the disability itself because outcomes may have been due to different types and intensities of services provided to the three groups. ${ }^{18}$ Nevertheless, their analysis raises questions about policies that depend on vocational rehabilitation to help persons with mental illness become self-sufficient.

Several studies show that targeted vocational rehabilitation programs, especially a type known as supported employment, can increase substantially the percentage of people who work. ${ }^{19}$ As its name implies, supported employment emphasizes continuous support for participants while they are seeking employment and after they obtain jobs. In all these studies supported employment increased labor force participation rates significantly more than the comparison group. What is less clear is how such interventions affect participants' total incomes and how successful they are at reducing welfare expenditures.

Evaluating a supported employment program in California, Meisel and her associates found that those who worked had average earnings of \$281 per month in fiscal year 1992 but, because they received less in entitlements, their total income was only $\$ 135$ higher than those who did not work. ${ }^{20}$ In a small study of persons enrolled in a Boston support employment program $(n=19)$, average monthly earnings for all participants increased by $\$ 154$ in 1990 dollars over earnings in the year prior to enrolment. ${ }^{21}$ Taxes and reductions in public benefits lowered the increase in average monthly income to about $\$ 41$. These studies suggest that persons with mental illness may derive relatively small short-term economic benefits from supported employment. However, neither of these studies considered support from family members or friends in their analysis and both reported benefits for only one year.

To learn more about the potential of vocational rehabilitation programs to help people with mental illness achieve economic self-sufficiency, we compared estimated income from earnings, government benefits and other sources before and after entry into either of two supported employment models over a period of 18 months. We also examined separately income changes associated with each vocational model, one of which was significantly more effective than the other in helping people obtain jobs. Our analysis focuses on economic benefits, excluding health insurance, to individuals. Although health coverage provided through Medicaid and Medicare is critically important for persons with severe mental illness, individual-level data on the specific value of such benefits were not available.

\section{The New Hampshire Study of Supported Employment}

We used data from a randomized trial of supported employment interventions for persons with mental illness to examine changes in individual income before and after enrolment in vocational rehabilitation. ${ }^{22}$ One intervention, Group Skills Training (GST), was based in a nonprofit vocational agency specializing in training for persons with mental retardation or mental illness. GST trained participants in how to select a job, how to negotiate the hiring process 
and how to maintain employment once on the job. Instruction in these skills lasted for eight weeks and participants were encouraged to complete this training before seeking a job. Staff also gave continuing support for participants after they found a job for the remainder of the 18-month study period. The second program, Individual Placement and Support (IPS), emphasized a rapid search for competitive jobs, continuing support after employment and integration of vocational and treatment services. It did not offer skills training prior to employment. Both programs provided ongoing support throughout the 18-month study period for participants who found jobs. Two local community mental health centers provided treatment services for all study participants and vocational services for those enrolled in IPS.

An earlier account of this study ${ }^{22}$ focused on the relative effectiveness of the two supported employment models. Vocational and clinical outcomes during the period after enrollment, including earnings, were reported as measures of program performance but changes in total income and benefit status were outside the scope of the initial paper. Here we draw on these and other additional data to examine the implications of supported employment for welfare and disability policies.

\section{Methods}

\section{Sample}

One hundred and forty-three adults with severe mental illness who lived in two contiguous service areas and were currently receiving mental health treatment were randomly assigned to IPS or GST for a period of 18 months. Participants met the following eligibility criteria: severe mental illness and major role dysfunction lasting at least two years; between 20 and 65 years of age; residence in their present community for at least six months; no hospitalizations in the month immediately preceding enrollment; no significant memory impairment or mental retardation, medical illness or substance dependence that would prevent them from participating in a training program and willingness to give informed consent. All potential participants were accepted if they attended four informational sessions about the study and met the criteria above.

Participants were enrolled in the study for 18 months. Two who dropped out of the study and another who died of cancer are excluded from this analysis. Due to missing data for some variables, an additional three participants were left out of our analyses, bringing the total number of valid cases to 137 . These six excluded participants did not appear to have significantly different characteristics from the larger sample.

The average age of study participants was 37 years (s.d. $=9.47)$. Slightly more than one-half $(51.7 \%)$ were female, $4.9 \%$ were members of a minority group, and $74 \%$ had completed high school. Participants reported working an average of 22.3 months (s.d. = 19.9) during the five years before they entered the study; 63\% $(n=89)$ were receiving Social Security Administration cash benefits (SSI or SSDI) at the beginning of the study. Diagnostically, $46.9 \%$ of enrollees had schizophrenia or a related psychotic disorder, $42.7 \%$ had a bipolar or other severe mood disorder, and $10.5 \%$ were in other classifications (primarily personality disorders). The Structured Clinical Interview for the DSMIII-R, ${ }^{23}$ administered by trained clinical research interviewers, was used to determine these diagnoses. In the year prior to the study, participants averaged 20.5 days of hospitalization. Data for IPS and GST participants are presented in Table 1. Extensive tests of randomization indicated that the two intervention groups were equivalent on almost all factors. For a more detailed description of the sample, see Drake et al. ${ }^{22}$

\section{Experimental Procedures}

The study was conducted in two metropolitan areas in New Hampshire with respective populations of approximately 120000 and 165000 including surrounding towns. Study participants were selected from among clients currently in treatment at two comprehensive community mental health centers, one in each city. Treatment for their mental disorders did not change after clients entered the study; they continued receiving the same types of service from the same provider. Classes for those assigned to GST were conducted in each of the two cities by the vocational rehabilitation agency; $38 \%$ of the participants assigned to GST failed to complete the training phase but remained in the study and continued to receive outreach and support from GST staff. ${ }^{24}$ Consistent with the intent-to-treat approach to evaluation and with the principle that program effectiveness comprises the ability to maintain client involvement as well as to be successful in achieving other goals, those who did not complete initial GST training were retained in our analysis. IPS clients met individually with an employment specialist from their local mental health center. Each mental health center conducted its own IPS program.

Table 1. Characteristics of IPS and GST participants ${ }^{\mathrm{a}}$

\begin{tabular}{|c|c|c|}
\hline Characteristic & $\begin{array}{c}\text { IPS } \\
n=71 \\
\text { (standard } \\
\text { deviation) }\end{array}$ & $\begin{array}{c}\text { GST } \\
n=66 \\
\text { (standard } \\
\text { deviation) }\end{array}$ \\
\hline Age & $\begin{array}{c}37 \\
(9.8)\end{array}$ & $\begin{array}{c}37 \\
(9.1)\end{array}$ \\
\hline Percent female & $51 \%$ & $52 \%$ \\
\hline Percent minority & $3 \%$ & $6 \%$ \\
\hline High school graduate & $77 \%$ & $71 \%$ \\
\hline Schizophrenia & $44 \%$ & $53 \%$ \\
\hline Months worked in past 5 years & $\begin{array}{c}20 \\
(18.9)\end{array}$ & $\begin{array}{c}23 \\
(21.1)\end{array}$ \\
\hline Days hospitalized in past year & $\begin{array}{c}21 \\
(50.3)\end{array}$ & $\begin{array}{c}20 \\
(48.6)\end{array}$ \\
\hline
\end{tabular}

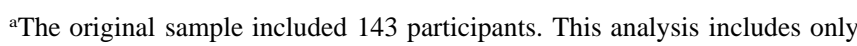
those who had complete income data, $n=137$. No differences were statistically significant. 


\section{Income measures}

Primary measures of income are from interviews with study participants. At baseline participants were asked to report the amount of income they had received from each of 11 sources during the past year. Interviews were conducted at six-month intervals after randomization, and participants reported the amount of income for the previous month. Income sources included earned income, Supplemental Security Income (SSI), Social Security Disability Insurance (SSDI), Aid to Families with Dependent Children (AFDC), Veterans Administration benefits, assistance from the Department of Housing and Urban Development, state and local welfare programs, grants for education or training, contributions from family and friends, assistance from private welfare agencies and unearned income. The values of Medicaid and Medicare benefits are not included in the income estimates we report in this paper because individuallevel data were not accessible. For those who received such benefits, it is likely that they had substantial value; average monthly payments for New Hampshire Medicaid beneficiaries with disabilities during the period covered by this study were $\$ 1283$.

Interview data were edited carefully; when possible, potential errors were checked with the participant or service provider. One-year baseline reports were multiplied by 1.5 to estimate earnings for the 18 months prior to enrolment. Estimates for income during the 18 months after assignment to a vocational program were derived by multiplying the one-month interview reports by six to obtain six-month estimates, and then summing the three six-month interview periods to produce an 18-month total. These self-reported earnings estimates were highly correlated $(r=0.78)$ with earnings reported on weekly employment logs kept by vocational staff during the enrolment period. Participants appeared to report payment amounts with reasonable accuracy, but they sometimes confused SSI with SSDI payments and vice versa (both come from the Social Security Administration). Although we were able to determine the actual source of payments in most cases, for purposes of analysis we have combined all Social Security income. Income taxes, including the personal portion of Social Security and Medicare taxes, were based on average payments by persons in the same earnings category as each study participant. All values are reported in 1992 dollars.

The overall analytic plan was to compare changes in total income and in income from various sources before and after enrolling in vocational rehabilitation. In secondary analyses, we explored the role of public benefits and of various clinical and functional factors that are thought to affect to changes in earnings. In the first step, we used Wilcoxon signed-rank tests for matched pairs to compare estimated income and taxes paid during the 18-month periods prior to and following enrollment in vocational rehabilitation. Mann-Whitney $U$-tests were used to compare income and taxes paid for IPS and GST participants within the baseline and study periods and to compare the amount of income change that each program produced. Subsequently, we used a series of $t$-tests and nonparametric tests (depending on the distribution of the variables being analyzed) to explore the relationship between Social Security benefits and income. Finally, we used ordinary least-squares regression to examine the effects of Social Security benefit status, diagnosis, symptoms, functioning, education, work history, experimental group, earnings during the baseline period and treatment site on changes in earnings after enrollment in a supported employment program.

\section{Vocational and Clinical Outcomes of the Two Supported Employment Programs}

IPS participants obtained competitive jobs at a rate almost twice that of GST participants (78.1\% versus $40.3 \%$ ). They were also more likely to work at a job for 20 or more hours per week and averaged 607 hours of work (s.d. = 843 ; median $=154$ ) in competitive jobs compared with 205 (s.d. $=400 ;$ median $=0$ ) for GST participants. Jobs achieved by both groups were predominantly part-time and included such positions as recreation coordinator, file clerk, grocery bagger and cook. Average wages were $\$ 5.59$ per hour for IPS and \$5.25 per hour for GST. Rates of employment for IPS were higher than GST in the first month following enrollment and remained higher throughout the study. Both groups showed significant improvement in global functioning, satisfaction with finances and with vocational services; there were no group differences for these or other nonvocational outcomes. For further details of program comparisons, see Drake et $a l .{ }^{22}$

\section{Changes in Income After Enrolling in Supported Employment}

Estimated total income, shown in Table 2, increased by an average of from $\$ 2060$ to $\$ 2848$ between the baseline and post-enrolment periods, or $\$ 114$ to $\$ 158$ per month. More than three-quarters of the increase was attributable to payments from government sources, primarily in the form of Social Security payments and educational grants. Analysis of federal housing assistance showed a nonsignificant trend towards higher benefits during the study period. Earnings and income from other sources did not increase significantly after enrollment.

Sources of income were quite different for the two groups. IPS participants' average work earnings grew by more than $\$ 800$ (median 220), while GST enrollees actually had slightly lower average earnings after enrolling in vocational rehabilitation (median change 0). Corresponding income taxes increased for IPS participants and declined for GST enrollees. Change in income from government sources tended to be greater for GST enrollees than for IPS participants. Increases in grants for education and housing subsidies accounted for most of this growth. Changes in SSI/SSDI income were not significantly different for the two groups.

The addition of 20 people to Social Security rolls after 
Table 2. Mean income 18 months before and 18 months after enrollment in supported employment $(n=137)$

\begin{tabular}{|c|c|c|c|c|c|c|}
\hline \multirow[t]{2}{*}{ Source } & \multicolumn{2}{|c|}{ Baseline } & \multicolumn{2}{|c|}{ Study } & \multicolumn{2}{|c|}{ Change } \\
\hline & $\begin{array}{c}\text { IPS } \\
\text { (standard } \\
\text { deviation) } \\
\text { [median] }\end{array}$ & $\begin{array}{c}\text { GST } \\
\text { (standard } \\
\text { deviation) } \\
\text { [median] }\end{array}$ & $\begin{array}{c}\text { IPS } \\
\text { (standard } \\
\text { deviation) } \\
\text { [median] }\end{array}$ & $\begin{array}{c}\text { GST } \\
\text { (standard } \\
\text { deviation) } \\
\text { [median] }\end{array}$ & $\begin{array}{c}\text { IPS } \\
\text { (standard } \\
\text { deviation) } \\
\text { [median] }\end{array}$ & $\begin{array}{c}\text { GST } \\
\text { (standard } \\
\text { deviation) } \\
\text { [median] }\end{array}$ \\
\hline Earned & $\begin{array}{c}2331 \\
(4469) \\
{[306]}\end{array}$ & $\begin{array}{c}1939 \\
(4311) \\
{[184]}\end{array}$ & 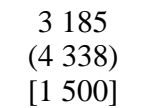 & $\begin{array}{c}1800 \dagger \dagger \\
(3061) \\
{[420]}\end{array}$ & $\begin{array}{c}854 * \\
(5261) \\
{[220]}\end{array}$ & 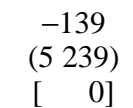 \\
\hline From government & $\begin{array}{c}8942 \\
(5238) \\
{\left[\begin{array}{ll}8 & 697\end{array}\right]}\end{array}$ & $\begin{array}{c}7656 \\
(5421) \\
{[8426]}\end{array}$ & $\begin{array}{c}9992 \\
(5442) \\
{[9546]}\end{array}$ & $\begin{array}{c}10368 \\
\left(\begin{array}{ll}5 & 658\end{array}\right) \\
{\left[\begin{array}{ll}10 & 035\end{array}\right]}\end{array}$ & $\begin{array}{c}1050^{*} \\
(3645) \\
{[621]}\end{array}$ & $\begin{array}{l}2712 * * \\
(6498) \\
{\left[\begin{array}{ll}1 & 270\end{array}\right]}\end{array}$ \\
\hline Other & $\begin{array}{c}2218 \\
(3505) \\
{[386]}\end{array}$ & $\begin{array}{c}1833 \\
(2870) \\
{[93]}\end{array}$ & $\begin{array}{c}2376 \\
(3968) \\
{[606]}\end{array}$ & $\begin{array}{c}2108 \\
(5062) \\
{[252]}\end{array}$ & $\begin{array}{c}158 \\
(3944) \\
{[0]}\end{array}$ & $\begin{array}{c}275 \\
(5402) \\
{[0]}\end{array}$ \\
\hline Total income & 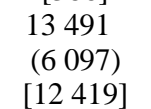 & $\begin{array}{l}11428 \\
\left(\begin{array}{lll}6 & 085\end{array}\right) \\
{\left[\begin{array}{lll}11 & 412\end{array}\right]}\end{array}$ & $\begin{array}{c}15553 \\
(5975) \\
{[14466]}\end{array}$ & $\begin{array}{l}14276 \\
(7245) \\
{\left[\begin{array}{ll}13 & 947]\end{array}\right.}\end{array}$ & $\begin{array}{l}2062 * * \\
(7433) \\
{[1756]}\end{array}$ & 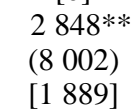 \\
\hline Taxes paid & $\begin{array}{r}367 \\
(741) \\
{[54]}\end{array}$ & $\begin{array}{r}270 \\
(654) \\
{[21]}\end{array}$ & $\begin{array}{r}443 \\
(660) \\
{[193]}\end{array}$ & $\begin{array}{c}255 \dagger \\
(437) \\
{[49]}\end{array}$ & $\begin{array}{c}76 \\
(840) \\
{[1]}\end{array}$ & $\begin{array}{c}-15 \\
(737) \\
{[0]}\end{array}$ \\
\hline
\end{tabular}

$* p<0.05, * * p<0.01$ for Wilcoxon signed ranks test for changes in values.

$\dagger P<0.05$, $\uparrow \uparrow p<0.01$ for Mann-Whitney $U$-test for IPS/GST comparisons within baseline, study and change categories.

participants were assigned to a vocational program played an important part in boosting average income from government sources. Payments for those who entered the study with Social Security benefits did not change significantly. A separate group of participants who did not report SSI or SSDI income either before or after enrolment $(n=22)$ had significantly lower incomes than Social Security beneficiaries in the 18 months before program assignment (\$9780 (s.d. 6176; median 8059) versus $\$ 13053$ (s.d. 5984; median 12 147); $t=2.35$, df $=135, p=0.02)$; however, their total income in the 18 months following enrollment was not significantly different from those who had such benefits (\$14 405 (s.d. 7587; median 13621 ) versus $\$ 15039$ (s.d. 6455; median 14 466); $t=0.41, \mathrm{df}=135, p=\mathrm{ns})$. The group without SSI/SSDI benefits increased their average income from all sources by $\$ 4625$ (s.d. 6752) after enrolling in vocational rehabilitation. Earnings and government grants for education or training showed significant increases for this group in the period after enrolment. Earned income accounted for over $60 \%$ of the total income growth for this group. Members of this group differed from those with benefits in four respects: they had more extensive work histories, slightly lower symptom scores on the Brief Psychiatric Rating Scale, ${ }^{25}$ slightly higher scores on the Global Assessment Scale ${ }^{26}$ and they tended to be less satisfied with their financial situation at the time they entered the study.

Participants who had SSI/SSDI benefits throughout the 36-month measurement period $(n=95)$ reported an increase of $\$ 1920$ (s.d. 7215) in average combined income between the baseline and study periods $(z=2.48, p=0.01)$. Most of this change (\$970) came in the form of government support for housing, education and training. SSI and SSDI income did not change significantly. Nominal changes in earnings (\$483) contributed about $25 \%$ of the increase. Income from family and other sources made up the remainder of the change.

A separate analysis of those who did not complete GST training $(38 \%)$ showed nonsignificant trends towards less extensive work histories (18.1 versus 27 months of work during the previous five years, $t=1.72$, $\mathrm{df}=50, p=0.09$ ), higher baseline symptom scores on the Brief Psychiatric Rating Scale (41.8 versus 38.6, $t=1.71, \mathrm{df}=50, p=0.09$ ) and a greater likelihood of having SSI or SSDI when they enrolled in GST (80.8\% versus $\left.60.5 \%, X^{2}=3.07, p=0.08\right)$. There were no differences in the proportion of persons with schizophrenia in the two groups. During the study period, non-completors worked significantly fewer hours than GST completors (62 versus 285, $t=2.26, \mathrm{df}=50, p<0.05)$ and earned less money (\$309 versus $\$ 1507, \mathrm{df}=50$, $t=2.16, p<0.05$ ).

Analysis of factors related to earnings changes are presented in Table 3. After examining the distribution of change scores and finding them normally distributed, we used ordinary least-squares regression to examine the relationship between earnings changes and a variety of clinical, programmatic and historical variables. For purposes of comparison, we contrasted logged and raw analyses and found similar results. For simplicity, we chose to report raw earnings in the analysis.

Those without Social Security benefits $(n=22)$ earned substantially more from work than those with benefits. As might be expected, those who did not receive benefits were different in other ways from those who did. At the time of randomization to a vocational program, they had more than twice as many months of work experience during the previous five years (27 versus 12 months), less severe 
Table 3. Changes in earnings after enrolling in supported employment $(n=137)$

\begin{tabular}{lc}
\hline Variable & $\begin{array}{c}\text { Regression } \\
\text { coefficient } \\
\text { (standard error) }\end{array}$ \\
\hline Social Security benefit status & $-3168^{* *}$ \\
$(0=$ no benefits, $1=$ received benefits) & $(881)$ \\
Diagnosis & 267 \\
$(1=$ bipolar and other, $0=$ schizophrenia) & $(628)$ \\
Work history & $45^{* *}$ \\
(months worked in past 5 years) & $(17)$ \\
Education & -413 \\
$(0=$ did not finish high school, $1=$ high school & $(686)$ \\
graduate) & \\
Vocational program type & $-1431^{*}$ \\
$(0=$ IPS, $1=$ GST) & $(590)$ \\
Site of mental health treatment & -456 \\
& $(651)$ \\
Baseline psychiatric symptoms & 22 \\
& $(44)$ \\
Baseline global functioning & \\
& 44 \\
Baseline earnings & $(49)$ \\
Adjusted $R^{2}$ & $-0.97^{* *}$ \\
$F$-value & $(0.07)$ \\
\hline
\end{tabular}

${ }^{a}$ Ordinary least-squares regression. All estimates are valued in 1992 dollars. ${ }^{b}$ Brief Psychiatric Rating Scale. A higher score indicates more severe symptoms.

${ }^{\mathrm{c}}$ Global Assessment Scale. A higher score indicates a higher level of functioning.

${ }^{*} p<0.05, * * p<0.01$.

psychiatric symptoms and higher functional levels. Of these factors, only work history was significantly associated with earnings. There were no differences in diagnosis.

The type of program to which participants were assigned affected earnings more strongly in the multiple regression model than in the simple pairwise comparisons. IPS participants earned over $\$ 1400$ more than GST enrollees.

\section{Discussion}

Incomes of persons with mental illness improved significantly after they enrolled in a supported employment program. Contrary to expectations, most of the additional income came from government sources rather than from earnings increases. Changes in earned income were relatively small and were statistically significant only for IPS participants. Average government income increased primarily because 20 people began receiving SSI or SSDI benefits after enrolling in a vocational rehabilitation program and because many enrollees received additional grants for education or training. Social Security records indicate that most participants reported to the government money earned from their jobs, but earnings did not appear to reduce Social Security benefits significantly. Although the estimated amount of tax paid fluctuated with earnings, changes in tax payments did not appear to be sufficiently large to affect work decisions.

Those who were not enrolled in SSI or SSDI earned over
$\$ 3000$ more from working than those who received the benefits and had only slightly lower average incomes than SSI/SSDI during the study period. The relationship between benefit status and earnings remained stable after all observed differences between the two groups were included in the statistical model. Despite the apparent strength of the effect, it cannot be taken as conclusive evidence that public payments reduce work motivation or earnings. Although we accounted for group differences by including those variables in our regression model, the coefficient for Social Security benefits presented in Table 3 is likely to be biased because it remains an endogenous variable (i.e., it does not meet the assumption of independence underlying the ordinary least-squares regression model). Normally an instrumental variable statistical analysis would have helped to remove bias and isolate the effects of Social Security status on earnings. Instrumental variable analysis is a two-stage estimation procedure that first attempts to remove the influence of factors (e.g. individual characteristics) that are correlated with the independent variable of interest (i.e. benefit status): this stage is known as constructing an instrument. In the second stage, the instrument is used to estimate a model that predicts more precisely the effects of the independent variable on the dependent measure. However, in this case the small number of people without benefits prevented construction of a reliable instrument, thus precluding such an analysis.

These caveats notwithstanding, the 22 participants without Social Security benefits clearly earned more and experienced more growth in total income after enrolling in supported employment than did those with benefits. Policy makers tend to think of vocational rehabilitation as a way of reducing dependence on public programs, but these findings suggest that they may produce even better results for those who are not yet enrolled in income support programs.

Lower earnings for participants with Social Security benefits may have been due to fears about losing benefits. If this was the case, participants may have been overly cautious. Most had earnings well below the typical level of substantial gainful activity (SGA). Benefits for those few who consistently exceeded the SGA earnings amount were protected by extended eligibility and 1619(b) rules well beyond the period covered by this study. Provisions that could have been used for reducing SGA income, such as a Plan to Achieve Self Support (PASS) account, were not widely used. No one actually lost benefits during the study.

Although few, if any, participants appear to have been in danger of losing income support or medical benefits, their apparent caution may have been rational in the face of the confusing rules that govern eligibility for such programs. Many waited months or even years to receive Medicaid and/or Medicare and loss of these benefits would have been catastrophic for them. Private insurance coverage rarely provides the same protections for persons with chronic illness as that provided by public insurance programs. When benefit limits are difficult to understand and the consequences of a wrong decision are high, caution makes sense.

The type of supported employment program to which 
participants were assigned did not make a significant difference in their average combined income. However, those in the IPS model earned substantially more from work and received about the same amount of government income during the study period as did those assigned to GST.

For participants, the relative economic benefits of the two vocational interventions are less clear. In choosing a program, individual preferences for competitive work over the greater security of Social Security benefits may be a more important consideration than expected differences in total income.

The relatively high number of people who failed to complete GST (almost two-fifths) contributed somewhat to outcome differences between that model and IPS. Even so, those who completed GST still earned significantly less than IPS participants. Perhaps IPS's more rapid placement in jobs helped to maintain participants' involvement. In dayto-day practice a program's ability to motivate and retain enrollees is a critically important part of its general effectiveness and should be taken into consideration when choosing an intervention.

Although a number of study participants began receiving SSI or SSDI payments after enrolling in a vocational program, we doubt that this change can be attributed solely to the programs themselves. The community mental health centers that supply treatment also help their clients apply for such benefits. It is likely that clinical staff shared responsibility for the increased enrolment. For this reason, reported results probably overstate public income growth due solely to the vocational rehabilitation programs.

We do not know whether supported employment produces benefits beyond the 18 months we studied. Our analysis of program effects covered a relatively brief time frame, making it impossible to detect such trends. By design, supported employment provides ongoing assistance. It is possible that the need for such support could diminish as workers and employers gain experience with one another. Further, the additional training and job experience that participants received initially may have long-run benefits. Although formal education was not associated with higher earnings in our study, participants earned an additional \$55 for each month of work experience in the preceding five years. Results for the IPS program suggest that some forms of supported employment may help build a work history more rapidly, increasing productive potential in subsequent years.

A question frequently raised about competitive employment programs for persons with severe mental illness is whether those interventions actually worsen health or mental health status. In this study there was no significant evidence of symptom exacerbation or of an increase in use of mental health services after enrollment in the program. Those results have been reported in greater detail elsewhere. .,6 $^{-1}$

Our income estimates should be viewed with some caution because they depend heavily on self-reports. Every effort was made to screen reports for accuracy, and our analysis shows that earnings reports compare favorably with weekly $\operatorname{logs}$ kept by vocational staff. Different reporting period lengths for baseline and study data may also have contributed to measurement error, although there is no reason to believe estimates are biased in a particular direction. We believe our data present a close approximation of actual income but they obviously lack the precision of reports verified by payers.

Self-reports also have some strengths. For example, by including assistance from family, friends and other sources, our data offer a more complete picture of income than could be obtained from public records alone. Because they were reported to an independent research interviewer, they may also have been less susceptible to reporting bias associated with a desire to minimize tax payments or to protect benefits.

These results are from a relatively small sample of people located in a state that may not be typical of the United States as a whole or of other countries. New Hampshire has a highly rated public mental health system, a small minority population and higher than average family income. Factors such as these should be considered carefully when thinking about the applicability of our findings to other geographic locations. Wages and job opportunities in more urban settings may differ from those that study participants experienced. Members of racial minority groups who are disabled appear to have a particularly difficult time finding work. ${ }^{27}$ Therefore, results of IPS or GST could be different in other areas. Although our data on changes in earnings are generally consistent with other studies, ${ }^{20,21}$ firm conclusions must await confirmation from subsequent research. Still, the data offer a level of detail about supported employment for people with severe mental disorders that is not available in larger studies. We believe this study provides unique information that is worthy of policy makers' careful consideration.

\section{Implications for Policy and Research}

As a rehabilitation strategy, supported employment and similar programs show significant promise. As a way of reducing spending for welfare and disability programs and of making persons with severe mental illness economically self-sufficient, work-based interventions such as supported employment are less effective. Finding a job does not quickly lead to economic independence for persons with severe mental illness. Even in the more successful program (IPS), spending for Social Security and educational grants tended to increase after enrollment.

Viewing vocational rehabilitation solely as a way of reducing welfare or disability rolls underestimates its potential. In the New Hampshire study, those who were not receiving Social Security benefits made the largest gains in earnings. Policies that limit vocational rehabilitation and training to specific welfare or disability benefit programs may overlook the group that can benefit most from such help.

In a broader sense, our analysis calls into question the viability of policies that would impose significant work requirements on disability beneficiaries. Although such policies may be appropriate for some welfare recipients, their extension to persons with psychiatric disabilities is likely to do more harm than good. This and other studies show that, with the right kind of intervention, labor force participation and earnings can be improved for persons with 
mental illness, but such gains are not synonymous with financial independence or with reduced dependence on public support. All participants in the New Hampshire study began with low incomes, and very few earned enough to pull themselves above federal poverty levels without public support. Many never found work.

Perhaps more than other disability groups, people with severe mental illness need a safety net. The chronic relapsing nature of schizophrenia and bipolar disorder appears to reduce the reliability of earnings as a primary source of support. Medicaid and Medicare coverage offers vital access to treatment and surpasses the limits imposed by most private policies. Losing such benefits is a genuine concern for those who choose to work.

Accumulated work experience coupled with rapidly improving treatment and rehabilitation techniques may continue to increase the earning potential for many persons. In the long term, more people with mental illness may become self-supporting; however, future promise should not take precedence over present reality in developing policies that affect the welfare of our most vulnerable populations.

This work was supported, in part, by grant No. MH00839 from the National Institute of Mental Health and grant No. MH-47650 from the National Institute of Mental Health and the Substance Abuse and Mental Health Services Administration.

\section{References}

1. Alverson M, Becker DR, Drake RE. An ethnographic study of coping strategies used by people with severe mental illness participating in supported employment. Psychosocial Rehabilitation J. 1995; 18: $115-128$.

2. Rogers ES, Walsh D, Masotta L, Danley K. Massachusetts Survey of Client Preferences for Community Support Services (Final Report). Boston, MA: Center for Psychiatric Rehabilitation, 1991.

3. Strauss JS, Harding CM, Silverman M, Eichler A, Liberman M. Work as treatment for psychiatric disorder: a puzzle in pieces. In: Ciardiello JA, Bell MD, eds. Vocational Rehabilitation of Persons with Prolonged Psychiatric Disorders. Baltimore, MD: Johns Hopkins Press, 1988.

4. Warner R, Polak P. The economic advancement of the mentally ill in the community: 2 economic choices and disincentives. Community Mental Health J. 1995; 31: 477-492.

5. Clark RE, Xie H, Becker DR, Drake RE. Costs and benefits of supported employment from three perspectives. J. Behav. Health Services Res. 1998; 25(1): 22-34.

6. Mueser KT, Becker DR, Torrey WC, Xie H, Bond GR, Drake RE, Dain BJ. Work and nonvocational domains of functioning in persons with severe mental illness: a longitudinal analysis. J. Nervous Mental Dis. 1997; 185(7): 419-426.

7. Andrews H, Barker J, Pittman J, Mars L, Streuning E, LaRocca N. National trends in vocational rehabilitation: a comparison of individuals with physical disabilities and individuals with psychiatric disabilities. J. Rehabilitation 1992; 58: 7-16.

8. Scott CG. Disabled SSI recipients who work. Social Security Bull. 1992; 55(26-36)

9. Rupp K, Scott CG. Trends in the characteristics of DI and SSI awardees and duration of program participation. Social Security Bull. 1996; 59: 3-21.

10. Muller LS. Disability beneficiaries who work and their experience under program work incentives. Social Security Bull. 1992; 55: 2-19.

11. Rosenheck R, Frisman L, Sindelar J. Disability compensation and work: a comparison of veterans with psychiatric and non-psychiatric impairments. Psychiatric Services 1995; 46: 359-65.

12. Moffitt R. Incentive effects of the U.S. welfare system: a review. $J$. Econ. Literature 1992; 30: 1-61.

13. Bound J. The health and earnings of rejected disability insurance applicants. Am. Econ. Rev. 1989; 79(3): 482-503.

14. Clark RE. Family costs associated with severe mental illness and substance use. Hospital Community Psychiatry 1994; 45(8): 808-813.

15. Caton CLM, Shrout PE, Dominguez B, Eagle PF, Opler LA, Cournos F. Risk factors for homelessness among women with schizophrenia. Am. J. Public Health 1995; 85(8): 1153-1156.

16. Caton CLM, Shrout PE, Eagle PF, Opler LA, Felix A, Dominguez B. Risk factors for homelessness among schizophrenic men: a casecontrol study. Am. J. Public Health 1994; 84(2): 265-230.

17. Dean DH, Dolan RC. Fixed-effects estimates of earnings impacts for the vocational rehabilitation program. J. Hum. Resources 1991; 26: 380-391.

18. Dean DH, Dolan RC. Assessing the role of vocational rehabilitation in disability policy. J. Policy Anal. Management 1991; 10: 568-587.

19. Bond GR, Drake RE, Mueser KT, Becker DR. Supported employmen for persons with severe mental illness: an update. Psychiatric Services 1997; 48: 335-346.

20. Meisel J, McGowen M, Patotzka D, Madison K, Chandler D Evaluation of AB 3777 Client and Cost Outcomes: July 1990 through March 1992. Lewin-VHI, 1993. Available from California Department of Mental Health, 1600 9th Street, Sacramento, CA 95814, USA.

21. Rogers ES, Sciarappa K, McDonald-Wilson K, Danley K. A benefitcost analysis of supported employment model for persons with psychiatric disabilities. Evaluation Program Planning 1995; 18(2): 105-115.

22. Drake RE, McHugo GJ, Becker DR, Anthony WA, Clark RE. The New Hampshire study of support employment for people with severe mental illness: vocational outcomes. J. Consulting Clin. Psychol. 1996; 64(2): 391-399.

23. Spitzer RL, Williams JB, Gibbon M. Structured Clinical Interview for DSM-III-R-Patient Version (SCID-P). New York: New York State Psychiatric Institute; 1988.

24. Drake RE, Becker DR, Xie H, Anthony WA. Barriers in the brokered model of supported employment for persons with psychiatric disabilities. J. Vocational Rehabilitation 1995; 5: 141-149.

25. Lukoff K, Liberman RP, Nuechterlein KH. Symptom monitoring in the rehabilitation of schizophrenic patients. Schizophrenia Bull. 1986; 12: $578-602$.

26. Endicott J, Spitzer RL, Fleiss JL, Cohen J. The Global Assessment Scale: a procedure for measuring overall severity of psychiatric disturbance. Arch. Gen. Psychiatry 1976; 33: 766-771.

27. Burkhauser RV, Haveman RH, Wolfe BL. How people with disabilities fare when public policies change. J. Policy Anal. Management. 1993; 12(2): 251-269. 